\title{
Mudas de Tectona grandis produzidas em diferentes níveis de saturação por bases do solo
}

\author{
Reginaldo de Oliveira ${ }^{1}$, Naiara Fernanda de Souza ${ }^{1}$, Marizane Pietroski ${ }^{1}$, Guilherme Ferreira \\ Ferbonink $^{1}$, Gustavo Caione ${ }^{1}$
}

${ }^{1}$ Universidade do Estado de Mato Grosso, Câmpus de Alta Floresta, Alta Floresta, Mato Grosso, Brasil. E-mail: reges23@outlook.com, naiarasouzaeng.f@outlook.com, agro_pietroski@hotmail.com, ferbonink@hotmail.com, gcaione@unemat.br

Recebido: 16/11/2017; Aceito: 26/02/2018.

\section{RESUMO}

A teca (Tectona grandis L. F) é uma espécie florestal que é favorecida pela elevação da saturação por bases do solo (V\%) devido, principalmente, à sua alta exigência em cálcio (Ca). Objetivou-se com este trabalho avaliar o efeito de doses de calcário e saturação de base alcançadas, sobre os atributos químicos de fertilidade do solo e no desenvolvimento vegetativo, acúmulo de matéria seca e qualidade de mudas de teca. O experimento foi conduzido em delineamento inteiramente casualizado. Os tratamentos foram quatro doses de calcário equivalentes a 0 (tratamento controle); 1,4; 3,7 e 5,2 $\mathrm{Mg} \mathrm{ha}^{-1}$, com oito repetições. Por ser um atributo que melhor representa o solo e diretamente relacionado às doses de calcário aplicadas, utilizou-se os valores de saturação por bases do solo (V\%) para apresentação e interpretação dos dados. Avaliou-se a altura de plantas, diâmetro do coleto, número de folhas, produção de massa seca e os índices de qualidade das mudas advindos das relações morfológicas. A aplicação de diferentes doses de calcário elevou o $\mathrm{V} \%$, aumentou o $\mathrm{pH}$, teores de $\mathrm{Ca}$ e $\mathrm{Mg}$ no solo e diminuiu a acidez potencial. $\mathrm{O}$ maior crescimento, acúmulo de biomassa e qualidade das mudas de teca, aos 75 dias após o transplantio, foi proporcionado pela saturação por bases média de $36 \%$

Palavras-chave: calcário, calagem, espécie florestal

\section{Tectona grandis seedlings produced in distinct levels of soil base saturation}

\begin{abstract}
Teak (Tectona grandis L. F) is a forest species that reacts well to elevation of soil base saturation (V\%), mainly due to its high calcium $(\mathrm{Ca})$ requirement. The aim of this work was evaluated the effect of limestone doses and soil base saturation levels on the chemical properties of soil, also in vegetative development, dry matter accumulation and quality of teak seedlings. The experiment was organized in completely randomized design. The treatment consists in four limestone doses: 0 (control); $1.4 ; 3.7$; and $5.2 \mathrm{Mg} \mathrm{ha}^{-1}$. The soil saturation values (V\%) were applied for the presentation and interpretation of the data, because it is considered an attribute that better represents the soil and is directly related to the limestone doses applied. The plant height, stem diameter, number of leaves, dry mass production and the quality indexes of seedlings from morphological relationships were evaluated. The application of different limestone doses increased the $\mathrm{pH}$, the $\mathrm{Ca}$ and $\mathrm{Mg}$ contents in soil and decreased the potential acidity. The highest growth, biomass accumulation and quality of teak seedlings at 75 days after transplanting was provided by the average base saturation of $36 \%$.
\end{abstract}

Key words: Limestone, Liming, Forest species. 


\section{Introdução}

A teca (Tectona grandis L. F.) é uma espécie florestal decídua que tem sua aplicação diversificada, sendo utilizada desde a fabricação de painéis até indústria naval e moveleira (FIGUEIREDO et al., 2006). É uma arbórea originária do continente asiático que se desenvolve bem em ambientes tropicais, contudo, demanda solos de alta fertilidade, bem drenados, relativamente profundos com textura média (FERNÁNDEZ-MOYA et al., 2015).

Alguns fatores como $\mathrm{pH}$ e teor de cálcio (Ca) trocável do solo, são primordiais para o bom desenvolvimento da teca. Assim observa-se em alguns estudos (FIGUEIREDO et al., 2006; HJELM; RYTTER, 2016) que o $\mathrm{pH}$ do solo ideal para teca varia de 6,5 a 7,5, com boa disponibilidade de $\mathrm{Ca}^{2+}$, sendo este um fator que pode limitar o sucesso do plantio, visto que em sua falta, as plantas têm seu desenvolvimento reduzido. Desta forma a espécie apresentou desenvolvimento diferenciado onde os teores de Ca trocável se encontravam elevados no solo (ALVARADO; FALLAS, 2004; FAVARE et al., 2012).

Devido à grande importância de uso e comércio, a teca tem sido implantada no Brasil. Entretanto, convencionalmente são destinadas áreas de baixa fertilidade para o seu plantio, dificultando o bom estabelecimento da floresta. Por apresentar baixa fertilidade, esses solos naturalmente apresentam teores baixos de Ca trocável, e valores elevados de alumínio trivalente $\left(\mathrm{Al}^{+3}\right)$ causador de rizotoxicidade, diminuindo a absorção de água e nutrientes pela planta (HORST et al., 2010; WEHR et al., 2017).

A baixa fertilidade do solo limita o desenvolvimento da teca, todavia, pode ser superada com a realização de correção do solo com calcário a fim de promover a elevação de saturação por bases do solo (V\%), pH e teores de $\mathrm{Ca}$ e magnésio (Mg) (VIEIRA; WEBER, 2017). Cabe ressaltar que a prática da calagem deve ser feita de forma racional e planejada posto que afeta o $\mathrm{pH}$ do solo diretamente e, consequentemente, a disponibilidade de nutrientes para as plantas (ALMEIDAet al., 2015; DO CARMO; SILVA, 2016).

A formação de mudas de qualidade contribui significativamente para a implantação de notáveis povoamentos florestais, conferindo maior resistência a campo, maiores taxas de sobrevivência e melhor desempenho frente às adversidades edafoclimáticas (TRAZZI et al., 2014). Deste modo, conhecer os níveis ideais de V\% para a espécie é essencial para uma boa formação de mudas. A calagem, considerada prática básica em qualquer sistema de cultivo de plantas, é específica para cada espécie e objetiva elevar V\% do solo para níveis ótimos (BAMBOLIM et al., 2015).

Objetivou-se com este trabalho avaliar o efeito de doses de calcário, e consequente $\mathrm{V} \%$ alcançadas sobre os atributos químicos de fertilidade do solo, desenvolvimento vegetativo, acúmulo de matéria seca e qualidade de mudas de teca.

\section{Material e Métodos}

O experimento foi realizado em vasos de polietileno, alocados em casa de vegetação na Universidade do Estado de Mato Grosso - UNEMAT, Câmpus Universitário de Alta Floresta-MT. Foi utilizado como substrato de cultivo o Latossolo Vermelho-Amarelo Distrófico (EMBRAPA, 2013), coletado na camada arável $(0-20 \mathrm{~cm})$, com as seguintes características químicas e granulométricas natural: $\mathrm{pH}$ em $\mathrm{CaCl}_{2}=4,2$; $\mathrm{pH}$ em água $=4,95 ; \mathrm{P}($ Mehlich 1$)=0,41 \mathrm{mg} \mathrm{dm}^{-3} ; \mathrm{Ca}=$ $1,53 \mathrm{cmol}_{\mathrm{c}} \mathrm{dm}^{-3} ; \mathrm{Mg}=0,42 \mathrm{cmol}_{\mathrm{c}} \mathrm{dm}^{-3} ; \mathrm{H}+\mathrm{Al}=6,02$ $\mathrm{cmol}_{\mathrm{c}} \mathrm{dm}^{-3} ; \mathrm{K}=0,015 \mathrm{cmol}_{\mathrm{c}} \mathrm{dm}^{-3}$; capacidade de troca de cátions $(\mathrm{CTC})=7,56 \mathrm{cmol}_{\mathrm{c}} \mathrm{dm}^{-3} ; \mathrm{V} \%=26$ e teor de argila $=46,9 \%$; silte $=4,6 \%$ e areia $=48,5 \%$.

$\mathrm{O}$ experimento foi conduzido em delineamento inteiramente casualizado, com quatro tratamentos e oito repetições. Os tratamentos foram quatro doses de calcário equivalentes a: 0 (controle); 1,$4 ; 3,7$ e 5,2 Mg $\mathrm{ha}^{-1}$, estimando elevar a saturação por bases do solo de $26 \%$ (natural), para $45 \% ; 75 \%$ e $95 \%$, seguindo o critério da elevação de V\% (RAIJ, 1991). Para tal, aplicou-se calcário Filler (30\% $\mathrm{CaO}$ e $21,1 \% \mathrm{MgO}$ ) com poder relativo de neutralização total (PRNT) de $100 \%$. Cada repetição foi composta de vaso com uma planta.

Após a incorporação do calcário, o solo foi incubado nos vasos durante 30 dias com teor de água próximo a $60 \%$ da capacidade de retenção de água. Para isso, inicialmente os conjuntos vaso + solo foram pesados e emergidos 2/3 de sua altura em água, saturando o solo por capilaridade. Após 24 horas, os vasos foram retirados e acondicionados em bancadas sobre suportes de madeira, para ocorrer a drenagem total da água gravitacional. Ao cessar a drenagem, os vasos foram pesados novamente, obtendo a capacidade de retenção de água do vaso, através da diferença entre peso saturado e peso após a drenagem.

A quebra de dormência das sementes de teca foi efetuada por meio de imersão em água por 72 horas. Posteriormente, as sementes foram colocadas para germinar cobertas com uma lona escura por 96 horas em uma sementeira contendo substrato composto de areia. Após 15 dias, houve a germinação de $90 \%$ das sementes (dados não apresentados).

Transcorrido o tempo de incubação do solo foi realizada a adubação básica em todos os tratamentos, incorporando ao solo $200 \mathrm{mg} \mathrm{dm}^{-3} \mathrm{de} \mathrm{P,} 150 \mathrm{mg} \mathrm{dm}^{-3} \mathrm{de}$ $\mathrm{K}$ e $200 \mathrm{mg} \mathrm{dm}^{-3}$ de N (MALAVOLTA et al., 1981), utilizando como fontes o Top Phos, cloreto de potássio e ureia, respectivamente. Também foram aplicados boro e zinco, usando as fontes ácido bórico e sulfato de zinco 
nas doses de $0,5 \mathrm{mg} \mathrm{dm}^{-3}$ de $\mathrm{B}$ e $1 \mathrm{mg} \mathrm{dm}^{-3}$ de $\mathrm{Zn}$, respectivamente, permanecendo incubados nos vasos por 15 dias com umidade na capacidade de campo.

Em seguida, realizou-se o transplantio das mudas, passando-as da sementeira para os vasos de polietileno com capacidade para $3 \mathrm{dm}^{3}$ contendo os tratamentos. Aos 20 dias após o transplantio foi realizada adubação de cobertura com 22,5 $\mathrm{mg} \mathrm{dm}^{-3}$ de $\mathrm{N}$, usando como fonte a ureia. Durante o período experimental, a irrigação foi efetuada para manter o teor de água do solo em aproximadamente $60 \%$ da capacidade de retenção de água através de monitoramento da diferença de pesos (peso do solo com $60 \%$ e peso antes da irrigação).

Aos 75 dias após o transplantio foi avaliada a altura da parte aérea com o auxílio de uma régua graduada em centímetros $(\mathrm{cm})$ e o diâmetro do coleto com paquímetro digital calibrado em milímetros (mm). Em seguida, foi separada a parte aérea e radicular, utilizando-se tesoura para seccionar no local de inserção do sistema radicular com a região do colo da planta. Após a separação e lavagem realizou-se a pesagem em balança analítica para obtenção da biomassa fresca.

As amostras da parte aérea e raízes foram acondicionadas em sacos de papel, levadas para secagem em estufa de ventilação forçada a temperatura de $65{ }^{\circ} \mathrm{C}$ até a obtenção do peso constante, após este período foram retiradas e aferido seu peso novamente a fim de obter a massa seca de raiz (MSR), massa seca da parte aérea (MSPA) e a massa seca total (somatório).

Com base nestes dados foram efetuados cálculos de índices que expressam a qualidade das mudas ou seja, a relação entre altura e diâmetro do coleto (ALT/DC), altura e massa seca da parte aérea (ALT/MSPA), massa seca da parte aérea e massa seca das raízes (MSPA/MSR) e índice de qualidade de Dickson (IQD), determinado segundo Dickson et al. (1960), em que $\mathrm{IQD}=[\mathrm{MST} /((\mathrm{ALT} / \mathrm{DC})+(\mathrm{MSPA} / \mathrm{MSR}))]$.

Ao término do experimento foi coletada uma amostra de solo de cada vaso, a qual foi seca ao ar e peneirada (malha de $2 \mathrm{~mm}$ de diâmetro), sendo, então, destinada à análise química, sendo analisado: o $\mathrm{pH}$ em $\mathrm{H}_{2} \mathrm{O}$ determinado em eletrodo de vidro; teores de $\mathrm{H}+$ $\mathrm{Al}$ (extraído com acetato de cálcio 0,5N ( $\mathrm{pH} 7.0$ ), analisado por titulometria com $\mathrm{NaOH} 0,025 \mathrm{~mol} \mathrm{~L}^{-1}$ ), $\mathrm{Ca}$ e $\mathrm{Mg}$ trocáveis (extraídos com $\mathrm{KCl} 1 \mathrm{~N}$, determinados por titulometria com EDTA 0,0125 mol L' ${ }^{1}$ ), $\mathrm{P}$ e o $\mathrm{K}$ disponíveis foram obtidos com a solução de Mehlich-1 ( $\left.\mathrm{HCl} 0,05 \mathrm{~mol} \mathrm{~L}{ }^{-1}+\mathrm{H}_{2} \mathrm{SO}_{4} 0,0125 \mathrm{~mol} \mathrm{~L}^{-1}\right)$ e determinados por espectrofotometria e fotometria de chama, respectivamente, seguindo a metodologia descrita pela (EMBRAPA, 2009).

Em função das características do solo, a aplicação das doses de calcário 0 (controle); 1,4; 3,7 e 5,2 Mg ha ${ }^{1}$, resultaram nas seguintes saturações por bases, V\% 26 (controle), $31 \%, 40 \%$ e $49 \%$, respectivamente. Por ser um atributo que melhor representa o solo e diretamente relacionado com as doses de calcário aplicadas, utilizouse os valores de V\% observada pela análise de solo no final do experimento, e não as doses de calcário aplicadas, para apresentação e interpretação dos dados.

Os dados obtidos foram submetidos à análise de variância pelo teste $\mathrm{F}$ e regressão polinomial a $5 \%$ de probabilidade, utilizando o programa estatístico SISVAR (FERREIRA, 2011). Os modelos foram testados, escolhendo os significativos e com maior coeficiente de determinação.

\section{Resultados e Discussão}

Inicialmente, houve elevada capacidade tampão do solo; as doses de calcário aplicadas a fim de elevar a saturação por bases de $26 \%$ para 45,75 e $95 \%$ resultaram em valores diferentes dos esperados, mesmo sendo utilizado calcário Filler com $100 \%$ de PRNT (Tabela 1). As saturações objetivadas de 45, 75 e 95 não foram atingidas, chegando apenas a V\% de 31, 40 e 49, respectivamente, ao término do experimento.

Portanto, estes foram os valores de saturação por bases utilizadas para apresentação e interpretação dos dados de desenvolvimento e qualidade das mudas de teca e não os valores objetivados. Estes resultados são coerentes com o descrito por Anjos et al. (2011), ao aplicarem calcário objetivando 40, 60 e $80 \%$ de saturação por bases do solo, obtiveram apenas 27,34 e $35 \%$, respectivamente. A absorção de bases (K, Ca e $\mathrm{Mg}$ ) pelas plantas foi um fator que contribuiu para este fato além do curto período transcorrido entre a aplicação de calcário e a análise de solo.

A aplicação de calcário proporcionou efeito sobre todos os atributos químicos do solo avaliados, exceto o $\mathrm{K}$ trocável e o $\mathrm{P}$ disponível (Tabela 1). Houve aumento

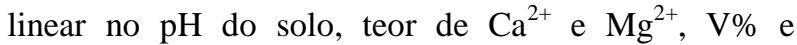
diminuição da acidez potencial $(\mathrm{H}+\mathrm{Al})$. Os teores de $\mathrm{K}^{+}$e $\mathrm{P}$ não foram influenciados, possivelmente por serem aplicados em quantidades equivalentes em todos os tratamentos (CARMO; SILVA, 2016), não havendo efeito das doses de calcário aplicadas na disponibilidade desses elementos.

Segundo Fageria et al. (2010), o efeito da calagem na elevação do $\mathrm{pH}$ e decréscimo na acidez potencial se deve ao aumento de concentração de hidroxilas $\left(\mathrm{OH}^{-}\right)$ na solução do solo, agindo sobre o hidrogênio $\left(\mathrm{H}^{+}\right)$, elevando o $\mathrm{pH}$ e complexando o $\mathrm{Al}^{3+}$ livre. Outro fator importante, relacionado ao $\mathrm{pH}$ dos solos, é a sua estreita relação com a disponibilidade de nutrientes essenciais para a teca (ZHOU et al., 2017). Nesse sentido, Alvarado e Fallas (2004) verificaram que solos com pH superior a 5,5 apresentam teores satisfatórios de macro e micronutrientes necessários, para o desenvolvimento da maioria das espécies florestais. 
Tabela 1 - pH em água, teor de fósforo disponível (P Mehlich-1), acidez potencial $(\mathrm{H}+\mathrm{Al})$, potássio, cálcio e magnésio trocáveis $(\mathrm{K}+, \mathrm{Ca}+2, \mathrm{Mg}+2)$, capacidade de troca catiônica a pH $7(\mathrm{~T})$, saturação por bases (V\%) e equações de regressão.

\begin{tabular}{|c|c|c|c|c|c|c|c|c|}
\hline \multirow{2}{*}{$\begin{array}{l}\text { Calcári } \\
\text { (Mg ha }\end{array}$} & \multirow{2}{*}{$\begin{array}{c}\mathrm{pH} \\
\mathrm{H}_{2} \mathrm{O}\end{array}$} & \multirow{2}{*}{$\begin{array}{c}\mathrm{P} \\
\left(\mathrm{mg} \mathrm{dm}^{-3}\right)\end{array}$} & $\mathrm{H}+\mathrm{Al}$ & $\mathrm{K}^{+}$ & $\mathrm{Ca}^{+2}$ & $\mathrm{Mg}^{+2}$ & CTC & $\mathrm{V}$ \\
\hline & & & \multicolumn{5}{|c|}{ 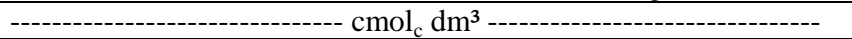 } & $\%$ \\
\hline 0 & 4,90 & 0,30 & 5,92 & 0,023 & 1,57 & 0,48 & 8,00 & 26 \\
\hline 1,4 & 5,02 & 0,29 & 5,60 & 0,025 & 1,92 & 0,56 & 8,13 & 31 \\
\hline 3,7 & 5,51 & 0,34 & 5,12 & 0,019 & 2,80 & 0,56 & 8,50 & 40 \\
\hline$\underline{5,2}$ & 6,40 & 0,33 & 4,44 & 0,035 & 3,66 & 0,60 & 8,73 & 49 \\
\hline Teste F & $1530,87 * *$ & $0,49 \mathrm{~ns}$ & $284,47 * *$ & $2,16 \mathrm{~ns}$ & $402,20 * *$ & $7,07 * *$ & $24,78 * *$ & $591,58 * *$ \\
\hline $\mathrm{CV}(\%)$ & 0,90 & 27,36 & 2,06 & 49,47 & 5,30 & 9,39 & 2,30 & 3,21 \\
\hline \multicolumn{2}{|c|}{ Parâmetros } & \multicolumn{4}{|c|}{ Equações de regressões } & \multicolumn{3}{|c|}{$\mathrm{R}^{2}$} \\
\hline \multicolumn{2}{|c|}{$\mathrm{pH}$} & \multicolumn{4}{|c|}{$y=4,7505+0,2758 x$} & \multicolumn{3}{|c|}{$0,89 * *$} \\
\hline \multicolumn{2}{|c|}{$\mathrm{H}+\mathrm{AL}$} & \multicolumn{4}{|c|}{$y=5,9788-0,2735 x$} & \multicolumn{3}{|c|}{$0,96 * *$} \\
\hline \multicolumn{2}{|c|}{$\mathrm{Ca}^{+2}$} & \multicolumn{4}{|c|}{$y=1,4652+0,3985 x$} & \multicolumn{3}{|c|}{$0,97 * *$} \\
\hline \multicolumn{2}{|c|}{$\mathrm{Mg}^{+2}$} & \multicolumn{4}{|c|}{$y=0,5034+0,0185 x$} & \multicolumn{3}{|c|}{$0,78 * *$} \\
\hline \multicolumn{2}{|c|}{ CTC } & \multicolumn{4}{|c|}{$y=7,9707+0,1447 x$} & \multicolumn{3}{|c|}{$0,99 * *$} \\
\hline \multicolumn{2}{|c|}{$\mathrm{V} \%$} & \multicolumn{4}{|c|}{$y=25,7875+4,4022 x$} & \multicolumn{3}{|c|}{$0,99 * *$} \\
\hline
\end{tabular}

** e ns: Significativo a 1\% e não significativo, respectivamente pelo teste $\mathrm{F}$. CV= Coeficiente de variação.

Com o aumento da dose de calcário houve elevação

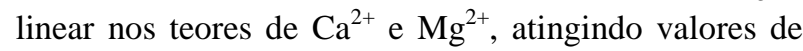
3,66 e $0,60 \mathrm{cmol}_{\mathrm{c}} \mathrm{dm}^{-3}$ respectivamente na dose de 5,2 $\mathrm{Mg} \mathrm{ha}^{-1}$ (Tabela 1). Este aumento deve-se à adição de carbonatos de cálcio $\left(\mathrm{CaCO}_{3}\right)$ e magnésio $\left(\mathrm{MgCO}_{3}\right)$ fornecidos pelo calcário, que ao dissociar-se no solo libera $\mathrm{Ca}^{2+}$ e $\mathrm{Mg}^{2+}$ (BERNARDINO et al., 2007; NATALE et al., 2007; ALMEIDA et al., 2015; CARMO; SILVA, 2016). Desta forma, o acréscimo nos teores de $\mathrm{Ca}^{2+}$ e $\mathrm{Mg}^{2+}$ no solo proporciona melhores condições de desenvolvimento para a teca, considerada uma espécie calcífera, tendo o Ca como nutriente mais requerido pela espécie (FAVARE et al., 2012).

Outro fator preponderante relacionado com o efeito do $\mathrm{Ca}^{2+}$ e do $\mathrm{Mg}^{2+}$ no desenvolvimento da teca em solos ácidos (ALVARADO; FALLAS, 2004), diz respeito ao ambiente de origem desta espécie, caracterizado por solos de caráter básico e fértil. Por tais motivos a calagem é imprescindível para o bom desenvolvimento da espécie, entretanto é essencial que seja feita de modo planejado, visto que em alto teor no solo, o $\mathrm{Ca}^{2+}$ pode precipitar ao $\mathrm{P}$ quimicamente, formando fosfato de cálcio, que $\mathrm{o}$ torna no solo temporariamente indisponível para as plantas (FERNÁNDEZ-MOYA et al., 2015).

Os resultados no aumento da CTC do presente estudo (Tabela 1), assemelham-se aos de Alleoni et al. (2005) ao aplicar calcário em um Latossolo, justificando o aumento da CTC devido à soma das bases trocáveis $(\mathrm{Ca}, \mathrm{Mg}$ e $\mathrm{K})$ e da acidez potencial $(\mathrm{H}+\mathrm{Al})$, ainda que o aumento de qualquer elemento destes na solução do solo elevaria a CTC. De fato, este aumento pode ter ocorrido devido ao aumento na concentração de $\mathrm{Ca}^{2+} \mathrm{e}$ $\mathrm{Mg}^{2+}$ na solução do solo, e possivelmente, parte do carbonato de cálcio e magnésio, que ainda não havia sofrido completa dissociação pode ser determinado na análise de solo, e não pela geração de novas cargas negativas no solo, observado por Bambolim et al.
(2015). Adicionalmente, o aumento das bases trocáveis do solo contribuiu para a elevação da saturação por bases $(\mathrm{V} \%)$.

Avaliando o efeito da V\% no crescimento das mudas de teca notou-se que, aos 75 dias após o transplantio, houve efeito na altura de plantas, acúmulo de matéria seca de raízes, parte aérea e acúmulo total (Tabela 2). Não houve efeito sobre o diâmetro de coleto e número de folhas das mudas; a ausência de resposta para estas variáveis se deve provavelmente aos teores de $\mathrm{Ca}^{2+} \mathrm{e}$ $\mathrm{Mg}^{2+}$ contidos no solo, suprindo as mínimas exigências nesta fase, como também observado em mudas de Cassia grandis (FREITAS et al., 2017) e ipê-amarelo (Tabebuia serratifolia) (VIEIRA; WEBER, 2017), demonstrando que são variáveis menos influenciadas pela calagem.

A Figura 1a mostra a análise do crescimento das mudas de teca em função da V\% do solo. Verificou-se comportamento quadrático, com altura máxima estimada de $30,6 \mathrm{~cm}$ quando o V\% foi de $38 \%$, representando incremento de $20,8 \%$ na altura das mudas comparado a V\% natural do solo $(25,37 \mathrm{~cm})$. A altura máxima citada acima, encontra-se dentro do padrão para um bom pegamento e facilidade de transporte para campo, que segundo Gonçalves et al. (2000), é de 20 a $35 \mathrm{~cm}$ e diâmetro de colo entre 5 a $10 \mathrm{~mm}$.

Estudando o desenvolvimento de ipê-amarelo, Vieira e Weber, (2017) atribuíram o maior crescimento das mudas à faixa de V\% em que há maior disponibilidade de nutrientes. Nesse sentido, Favare et al. (2012) verificaram faixa de melhor desenvolvimento de plantas de teca, aos 240 dias após o plantio quando se aplicou calcário objetivando V\% entre 60 e 80\%. Nessa perspectiva, os valores supracitados no presente estudo sobre o incremento na altura em função da V\% real do solo evidenciam a necessidade de se elevar a saturação por bases a níveis adequados, para que haja um bom desenvolvimento inicial das mudas de teca. 
Tabela 2 - Altura da parte aérea (ALT), diâmetro do coleto (DC), número de folhas (NF), massa seca da parte aérea (MSPA), massa seca das raízes (MSR) e massa seca total (MST) de mudas de Tectona grandis L. F, aos 75 dias após o transplantio sob diferentes saturações por bases do solo.

\begin{tabular}{|c|c|c|c|c|c|c|}
\hline \multirow{2}{*}{ V\% } & ALT & $\overline{\mathrm{DC}}$ & $\mathrm{NF}$ & MSR & MSPA & \multirow[t]{2}{*}{ MST } \\
\hline & $\mathrm{cm}$ & $\mathrm{mm}$ & & \multicolumn{2}{|c|}{-------- g planta ${ }^{-1}$} & \\
\hline 26 & 25,37 & 11,79 & 9,5 & 6,78 & 11,68 & 18,45 \\
\hline 31 & 30,19 & 11,74 & 10,12 & 8,06 & 13,46 & 21,52 \\
\hline 40 & 29,75 & 12,20 & 10,0 & 8,69 & 12,71 & 21,41 \\
\hline 49 & 26,75 & 11,36 & 10,0 & 5,97 & 9,46 & 15,44 \\
\hline Valor de F & $3,094 *$ & $1,983 \mathrm{~ns}$ & $1,157 \mathrm{~ns}$ & $8,232 * *$ & $6,780 * *$ & $11,720 * *$ \\
\hline $\mathrm{CV}(\%)$ & 13,38 & 6,03 & 7,36 & 16,43 & 15,96 & 12,41 \\
\hline
\end{tabular}

**; * e ns: significativo a 1\%; $5 \%$ de probabilidade e não significativo, respectivamente pelo teste $\mathrm{F}$. $\mathrm{CV}=$ Coeficiente de variação.
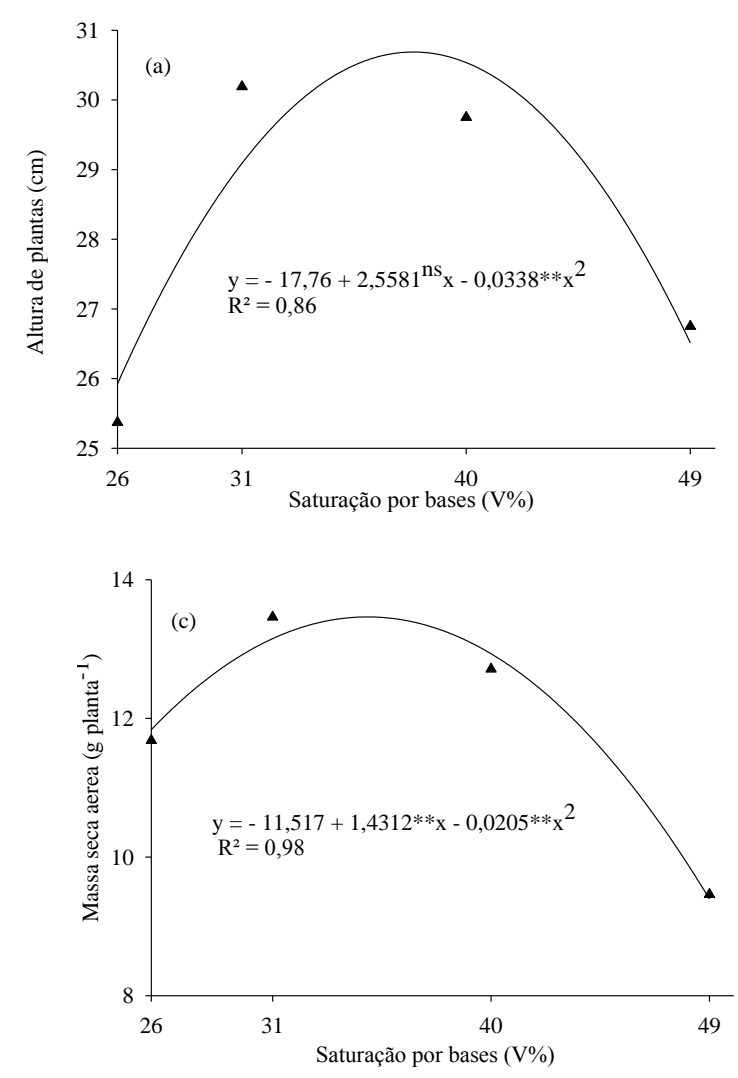
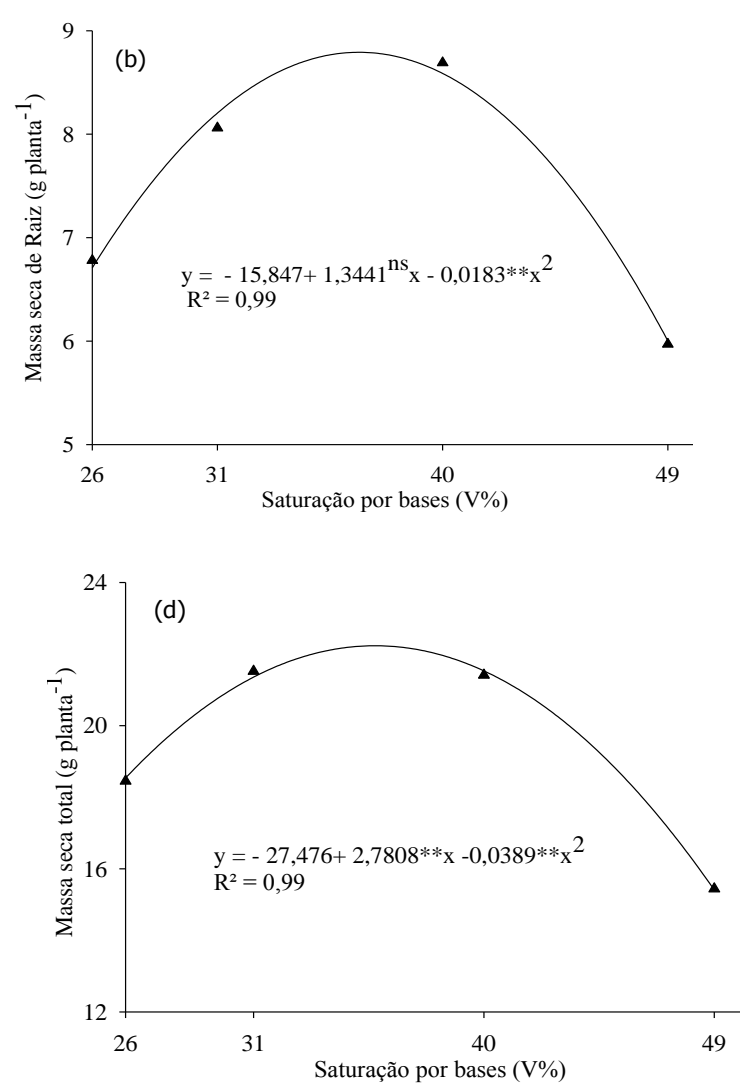

Figura 1. Altura das mudas de teca, Massa seca do sistema radicular, Matéria seca da parte aérea, e Matéria seca total (raízes e parte aérea) aos 75 dias após o transplantio. ns e **: não significativo e significativo a $1 \%$ de probabilidade, respectivamente.

Entretanto, é interessante ressaltar que a faixa de V\% ideal pode variar entre as espécies e em conformidade com o solo. Souza et al. (2008) relataram que as melhores mudas de jacarandá-de-espinho (Machaerium nictitans) produzidas em substrato de Argissolo Vermelho-Amarelo foram em V\% de 60, em Latossolo Vermelho-Amarelo Distrófico V\% de 70 e de 40\% em Latossolo Vermelho-Amarelo Álico.

Os dados de matéria seca de raízes, parte aérea e massa seca total se ajustaram a equações quadráticas, com máximo acúmulo de massa em V\% de 37\% (Figura 1b), 35\% (Figura 1c) e 36\% (Figura 1d), respectivamente. Supostamente, a elevação do $\mathrm{pH}$ e conseguinte neutralização do $\mathrm{Al}^{3+}$ tóxico favoreceram o desenvolvimento radicular, fato que contribuiu para maior absorção de água e nutrientes, como o $\mathrm{Ca}^{2+}$ principalmente, fornecido pelo calcário, agindo nos meristemas de crescimento protegendo as raízes a danos físicos e aumentando a sobrevivência das mudas a campo (BERNADINO et al., 2007; VIEIRA; WEBER, 2017).

Diante dos resultados, é notória a importância do aumento nos níveis de V\% do solo no aumento do sistema radicular, visto como um indicador confiável de desenvolvimento saudável em mudas de teca (ZHOU et al., 2012). 
Segundo Cruz et al. (2004), o aumento em matéria seca aérea representa mudas mais vigorosas e com maior capacidade fotossintética. Embora não observada diferença para o número de folhas, os efeitos positivos causados pela elevação da V\% do solo ao ambiente radicular possa ser responsável pelo desenvolvimento da parte aérea, proporcionando equilíbrio entre absorção e síntese na parte aérea. O incremento no acúmulo de MST é resultado, principalmente, do aumento nos teores de $\mathrm{Ca}^{2+}, \mathrm{Mg}^{2+}$ e da neutralização da acidez do solo, possibilitando maior disponibilidade e absorção de nutrientes (TUCCI et al., 2010; FAVARE et al.,2012), evidenciando a necessidade de se elevar a V\% do solo utilizado na produção de mudas florestais.

A relação entre as características morfológicas que expressam a qualidade das mudas foram influenciadas de maneira diferenciada pela elevação da V\% do solo (Tabela 3). Houve efeito do V\% do solo nas relações altura da parte aérea/massa seca da parte aérea (ALT/MSA) e índice de qualidade de Dickson (IQD) das mudas de teca; não houve efeito sobre as relações (ALT/DC, MSA/MSR e MSR/MSA). Bernardino et al. (2007) avaliando o efeito da V\% do solo em níveis de 14 a 70\% em substrato de Latossolo Distrófico, não verificaram os efeitos para as mesmas variáveis.

A Figura 2a demonstra o comportamento da relação entre altura e massa seca aérea (ALT/MSA) em função das V\% do solo. Essa relação aumentou linearmente com a elevação da V\%, ou seja, os maiores valores foram obtidos com a saturação de $49 \%$.

No entanto, valor muito elevado para este parâmetro não são interessantes uma vez que valores menores indicam plantas mais lignificadas e rústicas, com maior capacidade de sobrevivência em campo (CRUZ et al., 2004). A teca é altamente sensível à competição com gramíneas e outras invasoras por água, nutrientes e luz (MORETTI et al., 2014). Logo, relações maiores (ALT/MSA) podem ser benéficas, visto que a altura favorece $o$ estabelecimento inicial da planta se sobressaindo às possíveis plantas competidoras quando colocadas a campo.

Para o índice de qualidade de Dickson (IQD) (Figura 2b) observou-se maiores valores (7,02), em V\% de $33 \%$. Nota-se, que a aplicação de calcário, elevando a V\% do solo acima das condições supraótimas pode reduzir a qualidade de produção de muda de teca. Este índice pode variar em consequência da espécie utilizada e tratamento aplicado. Trazzi et al. (2014), demonstraram que o IQD de mudas de teca variou de 0,4 a 2,34 aplicando biossolidos ao substrato. Contudo, por ser um índice diretamente correlacionado a outros de equiparada importância, gera certa predição de robustez das mudas, assim, Freitas et al. (2017) sugerem que, tanto as adubações quanto as correções de substratos para produção de mudas sejam baseadas pelo IQD.

Tabela 3 - Relação entre altura da parte aérea com diâmetro do coleto (ALT/DC), altura da parte aérea com massa seca da parte aérea (ALT/MSPA), massa seca da parte aérea com massa seca das raízes (MSA/MSR), massa seca das raízes com massa seca da parte aérea (MSR/MSPA) e Índice de Qualidade de Dickson (IQD) de mudas de Tectona grandis L. F, aos 75 dias após o plantio sob diferentes saturações por bases do solo.

\begin{tabular}{cccccc}
\hline V\% & ALT /DC & ALT/MSPA $^{\mathrm{t}}$ & MSPA/MSR & MSR/MSPA & IQD \\
\hline 0 & 2,18 & 1,58 & 1,75 & 0,59 & 6,73 \\
26 & 2,56 & 1,80 & 1,70 & 0,61 & 6,86 \\
31 & 2,45 & 1,83 & 1,49 & 0,69 & 6,88 \\
40 & 2,37 & 1,99 & 1,63 & 0,66 & 5,21 \\
\hline Teste F & $1,915 \mathrm{~ns}$ & $3,971 * *$ & $0,672 \mathrm{~ns}$ & $0,886 \mathrm{~ns}$ & $4,416 *$ \\
CV $(\%)$ & 13,65 & 12,85 & 23,88 & 20,78 & 18,01 \\
\hline
\end{tabular}

**; * e ns: significativo a 1\%; $5 \%$ de probabilidade e não significativo, respectivamente pelo teste $\mathrm{F}$. $\mathrm{CV}=\mathrm{Coeficiente}$ de variação. ${ }^{\mathrm{t}}$ Dados transformados pela equação: Raiz quadrada de $\mathrm{Y}+1.0$ - SQRT $(\mathrm{Y}+1.0)$.
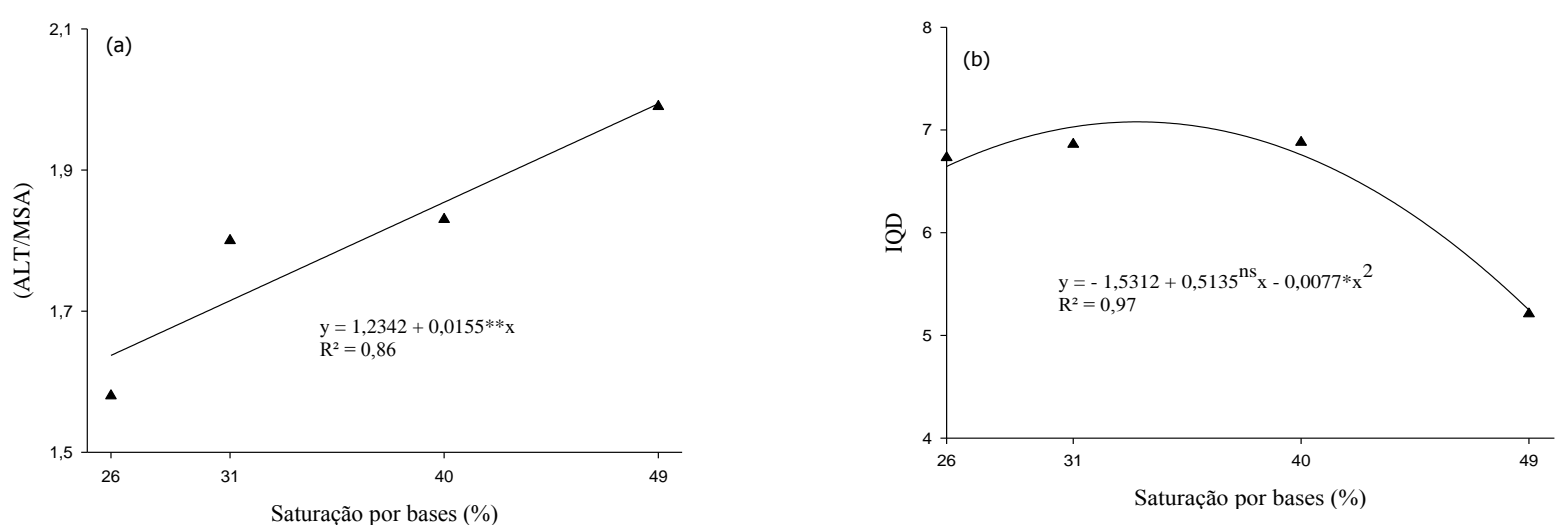

Figura 2. Relação entre a altura da parte aérea com a massa seca da parte aérea (ALT/MSA), e Índice de qualidade de Dickson (IQD) de mudas de teca em função da saturação por bases (V\%) do solo. **: significativo a 1\% de probabilidade. 
Considerando os resultados do presente estudo foi verificado que as condições químicas de disponibilidade de nutrientes como $\mathrm{Ca}^{2+}$ e $\mathrm{Mg}^{2+}$, aumento de $\mathrm{pH}$ e diminuição dos teores de $\mathrm{H}^{+}+\mathrm{Al}^{3+}$, foram influenciados pela elevação da V\% do solo por meio da calagem, e estes, certamente, contribuíram para o melhor desenvolvimento morfológico inicial das mudas de teca.

\section{Conclusões}

A calagem demonstrou ser prática importante, que elevou os níveis de $\mathrm{pH}$, teores de $\mathrm{Ca}$ e $\mathrm{Mg}$ trocáveis e diminuiu a acidez potencial no solo.

O maior crescimento, acúmulo de biomassa e qualidade das mudas de teca, aos 75 dias após o transplantio, foi proporcionado pela V\% média de $36 \%$.

\section{Referências Bibliográficas}

ALlEONI, L. R. F.; CAMBRI, M. A.; CAIRES, E. F. Atributos químicos de um Latossolo de cerrado sob plantio direto, de acordo com doses e formas de aplicação de calcário. Revista Brasileira de Ciência do Solo, Viçosa - MG, v. 29, n. 6, p. 923-934, 2005.

ALMEIDA, E. V. D.; FERNANDES, F. M.; CAIONE, G.; PRADO, R. DE M.; BOLIANI, A. C.; CORRÊA, L. D. S. Liming in growing mango cultivar Keitt in production. Communications in Soil Science and Plant Analysis, New York- NY, v. 46, n. 4, p. 430-438, 2015.

ALVARADO, A.; FALLAS, J.L. La saturación de acidez y el encalado sobre el crecimiento de la teca (Tectona grandis Lf) en suelos ácidos de Costa Rica. Agronomía Costarricense, San José, Costa Rica, v. 28, n. 1, p. 89-100, 2004.

ANJOS, J. L.; SOBRAL, L. F.; LIMA JUNIOR, M. A. Efeito da calagem em atributos químicos do solo e na produção da laranjeira. Revista Brasileira de Engenharia Agrícola e Ambiental, Campina Grande- PB, v. 15, n. 11, p. 1138-1142, 2011.

BAMBOLIM, A.; CAIONE, G.; SOUZA, N. F.; SEBENJUNIOR, G. F.; FERBONINK, G. F. Calcário líquido e calcário convencional na correção da acidez do solo. Revista de Agricultura Neotropical, Cassilândia-MS, v. 2, n. 3, p. 34-38, 2015.

BERNARDINO, D. C. S.; PAIVA, H. N.; NEVES, J. C. L.; GOMES, J. M.; MARQUES, V. B. Influência da saturação por bases e da relação Ca: $\mathrm{Mg}$ do substrato sobre o crescimento inicial de jacarandá-da-Bahia (Dalbergia nigra (Vell.) Fr. All. Ex Benth.). Revista Árvore, Viçosa-MG, v. 31, n. 4, p. 567$573,2007$.

CARMO, D. L.; SILVA, C.A. Condutividade elétrica e crescimento do milho em solos contrastantes sob aplicação de diversos níveis de calagem. Pesquisa Agropecuária Brasileira, Brasília-DF, v. 51, n. 10, p. 1762-1772, 2016.

CRUZ, C. A. F.; PAIVA, H. N. D.; GOMES, K. C. D. O.; GUERRERO, C. R. A. Efeito de diferentes níveis de saturação por bases no desenvolvimento e qualidade de mudas de ipê- roxo (Tebebuia impetiginosa (Mart.) Standley). Scientia Forestalis, Piracicaba-SP, v. 2, n. 66, p. 100-107, 2004.

DICKSON, A.; LEAF, A.L.; HOSNER, J.F. Quality appraisal of white spruce and white pine seedling stock in nurseries. Forestry Chronicle, Mattawa, v. 36, n. 1, p. 10-13, 1960.

EMBRAPA. EMPRESA BRASILEIRA DE PESQUISA AGROPECUÁRIA. Manual de análises químicas de solos, plantas e fertilizantes. Brasília-DF: Embrapa Solos, 2009. $624 \mathrm{p}$.

EMBRAPA. EMPRESA BRASILEIRA DE PESQUISA AGROPECUÁRIA. Sistema Brasileiro de Classificação de Solos. Rio de Janeiro-RJ: Centro Nacional de Pesquisa em Solos, 2013. 353 p.

FAGERIA, N. K.; DOS SANTOS, A. B.; MOREIRA, A. Yield, nutrient uptake, and changes in soil chemical properties as influenced by liming and iron application in common bean in a no-tillage system. Comunications in soil science and plant analysis, New York- NY, v. 41, n. 14, p. 1740-1749, 2010.

FAVARE, L. G.; GUERRINI, I. A.; BACKES, C. Níveis crescentes de saturação por bases e desenvolvimento inicial de teca em um Latossolo de textura média. Ciência Florestal, Santa Maria-RS, v. 22, n. 4, p. 693-702, 2012.

FERNÁNDEZ-MOYA, J.; ALVARADO, A.; MATA, R.; THIELE, H.; SEGURA, J. M.; VAIDES, E.; MARCHAMALO, S. M. Soil fertility characterisation of teak (Tectona grandis Lf) plantations in Central America. Soil Research, Melbourne-VIC, v. 53, n. 4, p. 423-432, 2015.

FERREIRA, D. F. Sisvar: um sistema computacional de análise estatística. Ciência e Agrotecnologia, Lavras-MG, v. 35, n. 6, p. 1039-1042, 2011.

FIGUEIREDO, E. O.; OLIVEIRA, L. C.; BARBOSA, L. K. P. Teca (Tectona grandis L.f.). Rio Branco-AC: Embrapa Acre, 2006. 24 p.

FREITAS, E. C. S.; PAIVA, H. N.; LEITE, H. G.; OLIVEIRA NETO, S. N. Crescimento e qualidade de mudas de Cassia Grandis linnaeus f. em resposta à adubação fosfatada e calagem. Ciência Florestal, Santa Maria- RS, v. 27, n. 2, p. 509-519, 2017. Disponível em: <https://periodicos.ufsm.br/cienciaflorestal/article/view/27732 > Acesso em: 16 nov. 2017.

GONÇALVES, J. D. M.; SANTARELLI, E. G.; MORAES NETO, S. D.; MANARA, M. P. Produção de mudas de espécies nativas: substrato, nutrição, sombreamento e fertilização. In: GONÇALVES, J. L. M.; BENEDETTI, V. (ed.) Nutrição e fertilização florestal. Piracicaba-SP: Instituto de Pesquisas e Estudos Florestais, 2000. p. 309 - 350.

HJELM, K.; RYTTER, L. The influence of soil conditions, with focus on soil acidity, on the establishment of poplar (Populus spp.). New forests, Dordrecht, v. 47, n. 5, p. 731$750,2016$.

HORST, W. J.; WANG, Y.; ETICHA, D. The role of the root apoplast in aluminium-induced inhibition of root elongation and in aluminium resistance of plants: a review. Annals of Botany, Oxford, Oxfordshire, v. 106, n. 1, p. 185-197, 2010. 
MALAVOLTA, E. Manual de Química Agrícola: Adubos e Adubação. 3. ed. São Paulo-SP: Editora Agronômica Ceres, $1981.594 \mathrm{p}$.

MORETTI, M. S.; TSUKAMOTO FILHO, A. D. A.; COSTA, R. B. D.; RONDON NETO, R. M.; MEDEIROS, R. A.; MELO SOUSA, R. A. T. D. Crescimento inicial de plantas de teca em monocultivo e sistema Taungya com milho em Figueiropolis D'Oeste, Estado de Mato Grosso. Scientia Forestalis, Piracicaba-SP, v. 42, n. 102, p. 269-277, 2014.

NATALE, W.; MELLO PRADO, R. D.; ROZANE, D. E.; ROMUALDO, L. M. Efeitos da calagem na fertilidade do solo e na nutrição e produtividade da goiabeira. Revista Brasileira de Ciência do Solo, Viçosa-MG, v. 31, n. 6, p. 475-1485, 2007.

RAIJ, B. V. Fertilidade do solo e adubação. São Paulo-SP: Agronômica Ceres, 1991. 343 p.

SILVA, A. R. M.; TUCCI, C. A. F.; LIMA, H. N.; FIGUEIREDO, A. F. Doses crescentes de corretivo na formação de mudas de mogno (Swietenia macrophylla King). Acta Amazonica, Manaus-AM, v. 37, n. 2, p. 195-200, 2007.

SOUZA, P. H. D.; NOGUEIRA DE PAIVA, H.; LIMA NEVES, J. C.; GOMES, J. M.; SILVA MARQUES, L. Influência da saturação por bases do substrato no crescimento e qualidade de mudas Machaerium nictitans (Vell.) Benth. Revista Árvore, Viçosa-MG, v. 32, n. 2, p. 193-201, 2008.
TRAZZI, P. A.; WINCKLER CALDEIRA, M. V.; FIALHO DOS REIS, E.; GOMES DA SILVA, A. Produção de mudas de Tectona grandis em substratos formulados com biossólido. Cerne, Lavras-MG, v. 20, n. 2, p. 293-302, 2014.

TUCCI, C. A. F.; LIMA, H. N.; GAMA, A. D. S.; COSTA, H. S.; SOUZA, P. A. D. Efeitos de doses crescentes de calcário em solo Latossolo Amarelo na produção de mudas de pau-debalsa (Ochroma lagopus sw., Bombacaceae). Acta Amazonica, Manaus-AM, v. 40, n. 3, p. 543-548, 2010.

VIEIRA, C.; WEBER, O. Base Saturation on Growth and on Nutrition of Yellow Ipê Seedlings. Floresta e Ambiente, Seropédica-RJ, v. 24, n. 1, p. 1-10, 2017.

WEHR, J. B.; BLAMEY, F. P. C.; SMITH, T. E.; MENZIES, N. W. Growth and physiological responses of teak (Tectona grandis Linn. f.) clones to $\mathrm{Ca}, \mathrm{H}$ and $\mathrm{Al}$ stresses in solution and acid soils. New Forests, Dordrecht, v. 48, n. 1, p. 137$152,2017$.

ZHOU, Z.; LIANG, K.; XU, D.; ZHANG, Y.; HUANG, G.; MA, H. Effects of calcium, boron and nitrogen fertilization on the growth of teak (Tectona grandis) seedlings and chemical property of acidic soil substrate. New Forests, Dordrecht, v. 43, n. 2, p. 231-243, 2012.

ZHOU, Z.; LIU, S.; LIANG, K.; MA, H.; HUANG, G. Growth and mineral nutrient analysis of teak (Tectona grandis) grown on acidic soils in south China. Journal of Forestry Research, Berlin, v. 28, n. 3, p. 503-511, 2017. 